\title{
Valorization of Mining Wastes as Raw Materials to the Production of Glasses and Glass-Ceramics
}

\author{
Pura Alfonso $^{1}$, Oriol Tomasa ${ }^{1}$, Maite Garcia-Valles ${ }^{2}$ \\ ${ }^{1}$ Dept. de Enginyeria Minera i Recursos Naturals, Universitat Politècnica de Catalunya \\ Av. De les Bases de Manresa 61-73, 08242 Manresa, Spain \\ Address, City, Country \\ maria.pura.alfonso@upc.edu; oriol.tomasa@upc.edu \\ ${ }^{2}$ Dept. Cristal·lografia, Mineralogia i Dipòsits Minerals, Universitat de Barcelona, \\ Av. De les Bases de Manresa 61-73, 08242 Manresa, Spain \\ maitegarciavalles@ub.edu
}

Mining wastes constitute a serious environmental risk. Vitrification is an alternative for stabilizing hazardous mining waste because it bonds their constituents in a glassy, ceramic or a glass-ceramic stable matrix. Several previous studies support this hypothesis. In addition, of the materials coming from the mining waste have a great potential as raw material for applications, such as the manufacture of ceramics, glasses and glass-ceramic products. Here we present an alternative of environmental remediation through the manufacture of glass and glass-ceramics using dukmps and tailings from the mining of metallic deposits. The obtained materials sequestrate the pollutant elements into the structure of the obtained materials. Thus it is proposed remediation for recycle mining waste into new products with new end uses. In different compositions of wastes the conditions of melting-crystallization characteristics and manufacture ceramic materials were determined. Mineralogy, texture, chemical properties and physical-mechanical characteristics of the new material obtained are presented. 